\title{
Kadınlarda Obezite ve Alt Üriner Sistem Semptomları*
}

\author{
Obesity and Lower Urinary Tract Symptoms in Women
}

\author{
Çiğdem BİLGE**, Nezihe KIZILKAYA BEJi゙***
}

İletişim/ Correspondence: Çiğdem BİLGE Adres/ Adress: İstanbul Üniversitesi Florence Nightingale Hemşirelik Fakültesi, Kadın Sağlığı ve
Hastalıkları Hemşireliği AD., Abide-i Hürriyet Cad. 34381, Şişli/ İstanbul Tel: 021244000 00/ 27076 Fax: 02122244990
E-mail: cigdemaydinbilge@gmail.com

$\ddot{O} Z$

Amaç: Bu çalışmanın amacı, kadınlarda obezitenin üriner şikayetlerle iliş̧isini belirlemektir.

Yöntem: Çalışma, İstanbul Üniversitesi İstanbul Tip Fakültesi Kadın Hastalıklarl ve Doğum Anabilim Dalı Jinekoloji ve Ürojinekoloji Polikliniği'nde Aralık 2008-Aralık 2009 tarihleri arasında yapıldı. Çalışmaya gebe olmayan, 20 yaş ve üzeri toplam $320 \mathrm{kadın}$ alınd. Obezite derecesi beden kitle indeksi (BKI) ile değerlendirildi. Veri toplama aracı olarak Üriner Semptom Profili (The Urinary Symptom Profile-USP) ve kişilerin sosyo-demografik özelliklerini belirleyen sorgulama formu kullanıldl. Üriner Semptom Profili (ÜSP)'nin Türkçe geçerlik ve güvenirlik çalıșması yapıldl.

Bulgular: Elde edilen veriler doğrultusunda, kadınların \% 40,3 'ünün BKI normal, \%35.6 s’ hafif şişman ve \%24.1'i şiş-

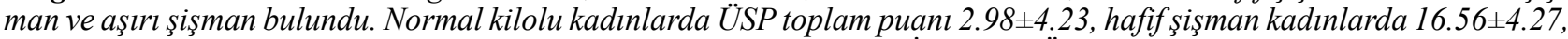
şişman/ aşırl şişman kadınlarda ise $24.18 \pm 4.41$ olarak bulundu. BKİye göre ÜSP toplam puan ve alt puan arasindaki fark istatistiksel olarak değerlendirildiğginde, toplam puan ve alt puan ortalamaları arasında anlamlı fark saptand

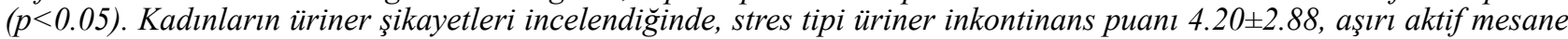

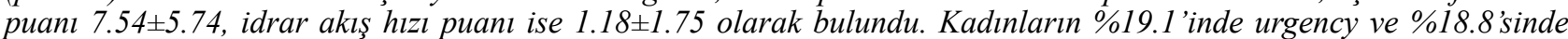
frequency şikayeti mevcuttur. ÜSP toplam faktörlerin puanın etkileyen faktörlerin etkileme düzeyini belirlemek amacıyla çoklu regresyon analizi uygulandl. USP'nin test-retest güvenirliği için 20 hastaya 2 hafta sonra tekrar uygulandl. Testretest güvenirliğinde her iki uygulama arasinda yüksek düzeyde korelasyon olduğu bulundu ( $r=0.93)$.

Sonuç: Beden kitle indeksi arttıkça üriner şikayetler artmaktadır.

Anahtar Kelimeler: Obezite, beden kitle indeksi, üriner inkontinans, aşırı aktif mesane, üriner semptom profili.

\begin{abstract}
Aim: The aim of this study is to determine the relationship between urinary complaints and obesity in women.

Method: This study conducted between December 2008 and December 2009 at the Istanbul University, Istanbul Faculty of Medicine Department of Obstetrics and Gynecology Outpatient Clinic of Gynecology and Urogynecology. Totaly 320 non-pregnant and over 20 (age) women participated in this study. Obesity degree was evaluated by body mass index (BMI). As data collection device The Urinary Symptom Profile-USP and query form (in order to determinate socio-demographic positions of participants) were used. Validity and reliability studies of USP (to Turkish) were done.

Results: It was determined that BMI of 40.3\% women was in normal limit, $35.6 \%$ lightly overwieght and $24.1 \%$ was obese and over obese. USP total points of normal weigth women was found 2.98土4.23, lightly overwiegth women's found

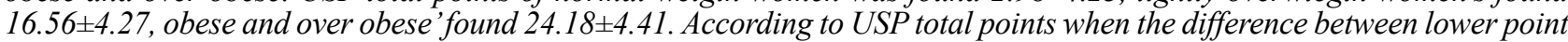
and total point was statisticaly examined, a significant difference between total and lower point was determined $(p<0.05)$. When women urinary complaints investigated type of stress urinary incontinence score was found $4.20 \pm 2.88$, overactive bladder score was found $7.54 \pm 5.74$ and urinary flow rate score was found $1.18 \pm 1.75 .19 .1 \%$ of the women complained of urgency and frequency are available 18.8\%. Multiple regression analysis model was used to determine the level of influence of the factors affecting the total factor points of USP. 20 patients for USP test-retest reliability were administered again two weeks later. Test-retest reliability at a high level has been found that the correlation between any two applications $(r=0.93)$. Conclusion: Body mass index increases urinary complaints increase too.
\end{abstract}

Keywords: Obesity, body mass index, urinary incontinence, overactive bladder, urinary sypmtom profile.

\footnotetext{
*İstanbul Üniversitesi Sağlık Bilimleri Enstitüsü Kadın Sağlı̆̆ı ve Hastalıkları Hemşireliği Anabilim Dalı Yüksek Lisans Tezi 2010, **Arş. Gör. İstanbul Üniversitesi Florence Nightingale Hemşirelik Fakültesi, ***Prof. Dr. İstanbul Biruni Üniversitesi Sağllk Bilimleri Fakültesi
}

Yazının gönderilme tarihi: 02.01.2015

Yazının basım için kabul tarihi: 27.05.2016 


\section{GíRiş}

Obezite, Dünya Sağlık Örgütü (DSÖ) tarafından "vücut yağ miktarının sağlığı bozacak şekilde aşırı ya da anormal birikmesi" olarak belirtilmiştir. Obezite, vücut yağ oranının, erkeklerde $\% 25$, kadınlarda $\% 35$ 'den fazla olması durumudur (Yüksel 2016). Türkiye Obezite Araştırma Derneği (TOAD) tarafindan, 2000-2005 yılları arasında 6 ilde (İstanbul, Konya, Denizli, Gaziantep, Kastamonu ve Kırklareli) 20 yaş üstü 13.878 bireyde yapılan "Türkiye Obezite Profili" çalışmasında bireylerin \%30.9'unun BKİ $30 \mathrm{~kg} / \mathrm{m}^{2}$ olduğu bulunmuştur. Ülkemizde 5 yılda bir tekrarlanan 15-49 yaş grubu kadınların çalışma kapsamına alındığ1 Türkiye Nüfus ve Sağlık Araştırması (TNSA) sonuçları incelendiğinde de kadınlarda obezite sıklığında son 10 yılda \%5.1 artış gözlenmiştir (T.C. Sağlık Bakanlığı 2013).

Obezite, üretra mukozasında hasara, kollajen miktarında azalmaya, üretra elastikiyetinin kaybına neden olmaktadır (Afşin 2008). Bununla beraber, obezite üriner inkontinansı kolaylaştırıcı önemli bir faktör olup durumun ciddiyetini de arttırmaktadır. Artan ağırlık pelvik kaslarda ve sinirlerde kronik ıkınma; gerilme, esneme ve zayıflamaya yol açar. Vücut kitle indeksinin, stres üriner inkontinansda anlamlı derecede yüksek değerler gösterdiği ortaya konulmuştur (UsluAtlaş 2008).

Üriner inkontinans bireyi sosyal, ekonomik ve psikolojik yönden de olumsuz etkileyen bir sorundur. Kadınlarda erkeklere daha fazla oranla görülmektedir. Üriner inkontinansın en sık görülen tipi başta stres inkontinans olmak üzere urge ve miks tiplerdir. Stres inkontinansin prevalansı ortalama \%16.1 olarak belirlenmiştir. Prevalans, 15-24 yaş grubunda \%4.7; 35-44 yaş grubunda \%21.6; 55-64 yaş grubunda \%25.1 ve 65 yaş üzerinde \%21.9 olarak tespit edilmiştir (Öztürk, Toprak ve Basa 2012).

Aşırı aktif mesane ise, ICS (Uluslararası Kontinans Derneği) tarafından metabolik veya diyabet, üriner sistem enfeksiyonu gibi patoloji olmadan, genellikle idrar yapma sıklığında artış ve nokturiyle birlikte sıkışma inkontinansının eşlik ettiği veya etmediği sıkışma sendromu olarak tanımlanmıştır (Coyne ve ark. 2011; Haylen ve ark. 2010). Tüm dünyada aşırı aktif mesane görülen kadınlar 50-100 milyon olarak saptanmıştır. Son yıllarda yapılan bazı çalışmalarda beden kitle indeksi (BKİ)'nin yüksek olması aşırı aktif mesane için risk faktörü olarak belirlenmiştir (Çankaya ve Oskay 2014; Lugo-Salcedo ve ark. 2013; Wang, Xu ve Hu 2011; Zhang ve ark. 2006)

Ancak, obezite ve üriner sistem semptomları arasındaki ilişkiyi değerlendiren çalışmalar sınırlı sayıdadır. Bu bağlamda iki aşamada gerçekleştirilmiş olan bu çalışmanın amacı, birinci aşamada, üriner sistemin semptom profili (the urinary symptom profile)'nin türkçe geçerlik ve güvenirliğini değerlendirmek, ikinci aşamada ise kadınlarda obezitenin üriner sistem şikayetleri ile ilişkisini belirlemektir.

\section{YÖNTEM}

\section{Araştırmanın Tipi}

Araştırma metadolojik ve ilişki arayıcı olarak plandı.

\section{Araştırmanın Yeri ve Zamanı}

İstanbul Üniversitesi, İstanbul Tip Fakültesi Kadın Hastalıkları ve Doğum Anabilim Dalı Jinekoloji ve Ürojinekoloji Polikliniği’nde Aralık 2008-Aralık 2009 tarihleri arasında yapılmıştır.

\section{Araştırmanın Evreni ve Örneklemi}

Araştırmanın evrenini, İstanbul Üniversitesi, İstanbul Tıp Fakültesi Kadın Hastalıkları ve Doğum Anabilim Dalı Jinekoloji ve Ürojinekoloji Polikliniğine Aralık 2008 - Aralık 2009 tarihleri arasında başvuran tüm kadınlar oluşturmuştur. Örneklem kapsamına ise, haftada iki gün (pazartesi, perşembe) bu polikliniklere gelen ve çalışmaya katılmayı kabul eden, çalışmaya alınma kriterlerine uyan tüm kadınlar dahil edilmiştir. Toplam 320 kadın ile görüşülmüştür. Araştırmaya alınma ölçütleri; gönüllü olarak katılması, 20 yaş ve üzeri olması, İletişim güçlüğü ve mental yetersizliğinin olmaması, gebe olmamasidır. 


\section{Veri Toplama Araçları ve Verilerin Toplanması}

Çalışmada, kadınların, BKİ, gebelik gibi demografik özelliklerini belirleyen soru formu ve üriner şikayetlerini değerlendiren üriner semptom profili (The Urinary Symptom Profile-USP) kullanılmıştır. Sorgulama formları, karş1lıklı görüşme yoluyla uygulanmıştır. ÜSP daha önce Türkçe'ye uyarlanmadığı için çalışma kapsamında öncelikle geçerlilik güvenilirlik analizleri yapılmıştır. ÜSP'nin test-retest güvenirliği için 20 hastaya 2 hafta sonra tekrar uygulanmıştır. Test-retest güvenirliğinde her iki uygulama arasında yüksek düzeyde korelasyon olduğu bulunmuştur (r= $0.93)$.

\section{Etik Konular}

Araştırmanın uygulanabilmesi için İstanbul Üniversitesi İstanbul Tıp Fakültesi Kadın Hastalıkları ve Doğum Anabilim Dalı'ndan ve kurumun Etik Kurulu'ndan yazılı izin alınmıştır. Kadınlardan, yazılı olarak bilgilendirilmiş izin formu alınmıştır.

\section{Verilerin Değerlendirilmesi}

Veriler SPSS paket programında, yüzde, ortalama, Mann- Whitney U, Ki kare testleri kullanılarak değerlendirilmiştir.

\section{BULGULAR}

Kadınların demografik özelliklerinin BKI'ne göre dağılımları Tablo 1'de sunulmuştur. Tablo 2'de kadınların üriner semptom profiline ilişkin puanlarının dağılımı yer almaktadır. Tablo 3'de kadınların BKİ'ne göre üriner semptom profili toplam ve alt boyut puan ortalamalarının karşılaştırılması yer almaktadır. BKI'ne göre üriner semptom profili toplam puan ve alt puan ortalamaları arasındaki fark incelendiğinde, toplam puan ve alt boyut puan ortalamaları arasinda istatistiksel olarak anlamlı fark saptanmıştır $(p<0.05)$. Farkın hangi gruplardan kaynaklandığını belirlemek için yapılan ileri analizde (Tukey analizi) her bir grup puanı diğer gruplara göre istatistiksel olarak anlamlı düzeyde yüksek bulunmuştur ( $\mathrm{p}=0.000$ ). BKİ ile ölçek toplam puan ve alt boyut puanları arasında pozitif yönde, ileri düzeyde ve istatistiksel olarak anlamlı bir ilişki vardır. Kadınların BKİ arttıkça ölçek puanları da artmaktadır.

Tablo 4'de kadınların BKI'ne göre üriner semptom profili toplam ve alt boyut puanlarının ilişkisi yer almaktadır. Kadınların BKİ arttıkça ölçek toplam puanı ve alt boyut puanları da artmaktadır (Tablo 4). Kadınların sosyo-demografik özelliklerine göre üriner semptom profili toplam ve alt boyut puan ortalamalarının karşılaştırılması Tablo 5'de sunulmuştur. Kadınların obstetrik özelliklerine göre üriner semptom profili toplam ve alt boyut puan ortalamalarının karş1laştırılması Tablo 6'da sunulmuştur.

Gebelik ve doğum sayısına göre üriner semptom profili toplam puan ve alt puan ortalamaları arasındaki fark incelendiğinde, puan ortalamaları arasında istatistiksel olarak anlamlı fark saptanmıştır $(\mathrm{p}=0.000)$.

Tablo 1. Kadınların Sosyo-Demografik Özellikleri ve Beden Kitle İndeksine Göre Dağılımı

\begin{tabular}{|c|c|c|}
\hline$(n=320)$ & Sayı (n) & $\%$ \\
\hline \multicolumn{3}{|l|}{ Yaş } \\
\hline $\begin{array}{l}20-29 \\
30-39 \\
40-49 \\
50-59 \\
60+\end{array}$ & $\begin{array}{l}79 \\
50 \\
56 \\
92 \\
43\end{array}$ & $\begin{array}{l}24.7 \\
15.6 \\
17.5 \\
28.8 \\
13.4\end{array}$ \\
\hline \multicolumn{3}{|l|}{ Medeni Durum } \\
\hline $\begin{array}{l}\text { Evli } \\
\text { Bekar /Boşanmış }\end{array}$ & $\begin{array}{c}247 \\
73\end{array}$ & $\begin{array}{l}77.2 \\
22.8\end{array}$ \\
\hline \multicolumn{3}{|l|}{ Eğitim Durumu } \\
\hline $\begin{array}{l}\text { Okur yazar değil / Okur yazar } \\
\text { İlköğretim } \\
\text { Lise } \\
\text { Üniversite }\end{array}$ & $\begin{array}{l}56 \\
93 \\
86 \\
85\end{array}$ & $\begin{array}{l}17.5 \\
29.1 \\
26.9 \\
26.6\end{array}$ \\
\hline \multicolumn{3}{|l|}{ Çalışma Durumu } \\
\hline $\begin{array}{l}\text { Çalışıyor } \\
\text { Çalışmıyor }\end{array}$ & $\begin{array}{l}190 \\
110\end{array}$ & $\begin{array}{l}59.4 \\
40.6\end{array}$ \\
\hline \multicolumn{3}{|l|}{ Gelir Durumu } \\
\hline $\begin{array}{l}\text { Gelirim giderimden az } \\
\text { Gelirim giderime eşit }\end{array}$ & $\begin{array}{l}184 \\
136\end{array}$ & $\begin{array}{l}57.5 \\
42.5\end{array}$ \\
\hline \multicolumn{3}{|l|}{ BKİ } \\
\hline $\begin{array}{l}\text { 18.5-24.99 (normal) } \\
25.0-39.99 \text { (hafif şişman) } \\
40 \text { ve } \uparrow \text { (şişman ve aşı1ı şişman) }\end{array}$ & $\begin{array}{c}129 \\
114 \\
77\end{array}$ & $\begin{array}{l}40.3 \\
35.6 \\
24.1\end{array}$ \\
\hline
\end{tabular}


Tablo 2. Kadınların ÜSP Alt Gruplarına İlişkin Puanlarının Dağılımı

\begin{tabular}{|c|c|c|c|c|}
\hline$(n=320)$ & $\mathbf{X} \pm \mathbf{S S}$ & Med. & Min. & Max. \\
\hline Stres tipi idrar kaçırma (0-9 puan) & $4.20 \pm 2.88$ & 5 & 0 & 9 \\
\hline Aşırı aktif mesane (0-21 puan) & $7.54 \pm 5.74$ & 8 & 0 & 19 \\
\hline İdrar akış hızında yavaşlama (0-9 puan) & $1.18 \pm 1.75$ & 0 & 0 & 7 \\
\hline Toplam puan (0-39 puan) & $12.92 \pm 9.67$ & 14 & 0 & 34 \\
\hline
\end{tabular}

Tablo 3. Kadınların BKİ'ne Göre ÜSP Toplam ve Alt Boyut Puan Ortalamalarının Karşılaştırılması

\begin{tabular}{|c|c|c|c|c|c|}
\hline \multirow{3}{*}{ Üriner Semptom Profili } & \multicolumn{3}{|c|}{ BKİ } & & \\
\hline & $\begin{array}{c}18.5-24.99 \\
(\text { Normal) } \\
(n=129)\end{array}$ & $\begin{array}{c}\text { 25.0-39.99 } \\
\text { (Hafif Şişman) } \\
(n=114)\end{array}$ & $\begin{array}{c}\text { 40.00 ve } \uparrow \\
\text { (Şişman ve } \\
\text { Aşırı Şişman) } \\
(n=77)\end{array}$ & & \\
\hline & $\mathrm{X} \pm \mathrm{SD}$ & $\mathrm{X} \pm \mathrm{SD}$ & $\mathrm{X} \pm \mathrm{SD}$ & $\mathrm{X}_{\mathrm{KW}^{*}}^{2}$ & $\mathrm{p}$ \\
\hline $\begin{array}{l}\text { Stres tipi idrar kaçırma } \\
\text { Aşırı aktif mesane } \\
\text { İdrar akış hızında yavaşlama } \\
\text { Toplam Puan }\end{array}$ & $\begin{array}{l}1.16 \pm 1.65 \\
1.71 \pm 2.51 \\
0.11 \pm 0.38 \\
2.98 \pm 4.23\end{array}$ & $\begin{array}{c}5.56 \pm 1.0 \\
9.57 \pm 2.77 \\
1.43 \pm 1.61 \\
16.56 \pm 4.27\end{array}$ & $\begin{array}{c}7.26 \pm 0.89 \\
14.40 \pm 2.43 \\
2.62 \pm 2.15 \\
24.18 \pm 4.41\end{array}$ & $\begin{array}{l}260.38 \\
253.65 \\
141.04 \\
257.37\end{array}$ & $\begin{array}{l}0.000 \\
0.000 \\
0.000 \\
0.000\end{array}$ \\
\hline
\end{tabular}

*Kruskal-Wallis Analizi $\mathrm{SD}=2$

Tablo 4. Kadınların BKİne Göre ÜSP Toplam ve Alt Boyut Puanlarının İlişkisi

\begin{tabular}{|l|c|c|}
\hline ÜSP & Beden Kitle İndeksi & p \\
\hline Stress tip idrar kaçırma & 0.82 & 0.000 \\
\hline Aşırı aktif mesane & 0.85 & 0.000 \\
\hline İdrar akış hızı & 0.57 & 0.000 \\
\hline Toplam Puan & $\mathbf{0 . 8 5}$ & $\mathbf{0 . 0 0 0}$ \\
\hline
\end{tabular}

Gebelik ve doğum sayısı arttıkça ölçek alt grup puanları da artmaktadır (Tablo 6).

Kadınların gebelik ve doğum sayıları ile ölçek toplam puanı ve alt boyut puanları arasında pozitif yönde, güçlü ve çok güçlü düzeyde ve istatistiksel olarak ileri derecede anlamlı bir ilişki vardır (Tablo 7).

ÜSP toplam puanını etkileyen faktörlerin etkilenme düzeyini belirlemek amacıyla çoklu regresyon analizi yapılmıştır. Belirleyicilik katsayısı $\mathrm{r}^{2}=0.86$ olup, ölçek puanındaki değişimin \%86'sı yaş, BKİ, doğum sayısı ve diyabet hastalığındaki değişimlere bağl1 olduğunu göstermektedir. Durbin-Watson testine göre de 1.69 saptanmıştır. Bu değer 2'ye yakın bir değer olduğu için model uyumlu bulunmuştur. ANOVA tablosunda F analiz sonucuna göre oluşturulan model istatistiksel olarak anlamlı, doğrusal bir modeldir $(\mathrm{F}=464.05, \mathrm{SD}=4, \mathrm{p}=0.000)$. Çoklu regresyon analizine göre üriner semptom profili puanını etkileyen bağımsız değişkenler Tablo 8'de sunulmuştur.

Üriner semptom profili toplam puan $1=-20.318+$ 0.132 (yaş) +0.859 (BKİ) +2.963 (diyabet) +1.707 (doğum sayısı) olarak hesaplanmıştır. Bu regresyon grubuna göre, yaşta meydana gelecek 1 birimlik artış ölçek puanını 0.132 arttırmaktadır. BKİ 1 birim arttığında ölçek puanı 0.859 artmaktadır. Diyabet sıkl1ğındaki 1 birimlik artış ölçek puanını 2.963 arttırmaktadır. Doğum sayısında meydana gelecek 1 birimlik artış ölçek puanını 1.707 arttırmaktadır. Oluşturulan bu regresyon modeli, tüm bağımsız değişkenlerin $\mathrm{t}$ testinde anlamlı bulunması nedeniyle başarılı kabul edilmiştir $(\mathrm{t}=-15.34, \mathrm{p}=0.000) . \% 95$ güven aralı̆̆ 1 değerlendirildiğinde, regresyon modelindeki tüm değişkenlerin güven aralığ1 0'1 içermemektedir. Bu nedenle değişken katsayıları evreni yansıtma açısından 
Tablo 5. Kadınların Sosyo-Demografik Özelliklerine Göre ÜSP Toplam ve Alt Boyut Puan Ortalamalarının Karşılaştırılması

\begin{tabular}{|c|c|c|c|c|c|c|c|c|}
\hline \multirow{4}{*}{$\ddot{\mathbf{U S P}}$} & \multicolumn{5}{|c|}{ Sosyo-Demografik Özellikler } & & & \\
\hline & \multicolumn{5}{|c|}{ Yaş Grupları } & & & \\
\hline & $\begin{array}{c}20-29 \\
(n=79)\end{array}$ & \multirow{2}{*}{$\begin{array}{c}\begin{array}{c}\mathbf{3 0 - 3 9} \\
(\mathbf{n}=\mathbf{5 0})\end{array} \\
\mathrm{X} \pm \mathrm{SD} \\
\end{array}$} & $\begin{array}{c}40-49 \\
(n=56)\end{array}$ & $\begin{array}{c}50-59 \\
(n=92)\end{array}$ & $\begin{array}{l}60 \text { ve } \uparrow \\
(n=43)\end{array}$ & & & \\
\hline & $\mathrm{X} \pm \mathrm{SD}$ & & $\mathrm{X} \pm \mathrm{SD}$ & $\mathrm{X} \pm \mathrm{SD}$ & $\mathrm{X} \pm \mathrm{SD}$ & \multicolumn{2}{|c|}{$\mathrm{X}_{\mathrm{KW}^{*}}^{2}$} & $\mathrm{p}$ \\
\hline Stres tipi idrar kaçırma & $0.10 \pm 0.65$ & $4.24 \pm 2.12$ & $4.79 \pm 1.62$ & $6.14 \pm 1.55$ & $6.74 \pm 1.16$ & \multicolumn{2}{|c|}{182.983} & 0.000 \\
\hline Aşırı aktif mesane & $0.19 \pm 1.21$ & $6.90 \pm 4.22$ & $8.11 \pm 4.09$ & $11.29 \pm 3.51$ & $13.02 \pm 3.69$ & \multicolumn{2}{|c|}{181.264} & 0.000 \\
\hline $\begin{array}{l}\text { İdrar akış hızında } \\
\text { yavaşlama }\end{array}$ & 0 & $0.58 \pm 1.27$ & $1.18 \pm 1.65$ & $1.84 \pm 1.78$ & $2.67 \pm 2.24$ & \multicolumn{2}{|c|}{100.051} & 0.000 \\
\hline \multirow[t]{6}{*}{ Toplam Puan } & $0.29 \pm 1.86$ & $11.72 \pm 6.76$ & $14.07 \pm 6.48$ & $19.27 \pm 5.86$ & $22.44 \pm 6.07$ & \multicolumn{2}{|c|}{185.312} & 0.000 \\
\hline & \multicolumn{5}{|c|}{ Eğitim Düzeyi } & & & \\
\hline & \multicolumn{3}{|c|}{$\begin{array}{l}\text { Okur yazar } \\
\text { değil / Okur } \\
\text { yazar }(n=56)\end{array}$} & $\begin{array}{c}\text { Lise } \\
(n=86)\end{array}$ & $\begin{array}{l}\text { Üniversite } \\
(\mathbf{n}=\mathbf{8 5})\end{array}$ & & & \\
\hline & \multicolumn{5}{|c|}{ Gelir Durumu } & & & \\
\hline & \multicolumn{3}{|c|}{$\begin{array}{c}\text { Gelirim giderimden } \mathrm{az} \\
(\mathrm{n}=184)\end{array}$} & \multicolumn{2}{|c|}{$\begin{array}{l}\text { Gelirim giderime eşit } \\
\qquad(\mathrm{n}=136)\end{array}$} & & & \\
\hline & \multicolumn{3}{|c|}{$\mathrm{X} \pm \mathrm{SD}$} & \multicolumn{2}{|c|}{$\mathrm{X} \pm \mathrm{SD}$} & $\mathrm{U}$ & $\mathrm{z}$ & $\mathrm{p}$ \\
\hline Stres tipi idrar kaçırma & \multicolumn{3}{|c|}{$4.90 \pm 2.72$} & \multicolumn{2}{|c|}{$3.25 \pm 2.82$} & 8282 & -5.25 & 0.000 \\
\hline Aşırı aktif mesane & \multicolumn{3}{|c|}{$9.15 \pm 5.62$} & \multicolumn{2}{|c|}{$5.36 \pm 5.16$} & 7815 & -5.80 & 0.000 \\
\hline $\begin{array}{l}\text { İdrar akış hızında } \\
\text { yavaşlama }\end{array}$ & \multicolumn{3}{|c|}{$1.66 \pm 1.94$} & \multicolumn{2}{|c|}{$0.54 \pm 1.20$} & 7947.5 & 6.07 & 0.000 \\
\hline \multirow[t]{4}{*}{ Toplam Puan } & \multicolumn{3}{|c|}{$15.71 \pm 9.52$} & 9.1 & 8.57 & 7580.5 & -6.082 & 0.000 \\
\hline & & & Çalışma Dur & $\mathrm{mu}$ & & & & \\
\hline & & alışıyor $(n=1$ & 190) & Çalışmı & $r(n=130)$ & & & \\
\hline & & $\mathrm{X} \pm \mathrm{SD}$ & & & SD & $\mathrm{U}$ & $\mathrm{z}$ & $\mathrm{p}$ \\
\hline Stres tipi idrar kaçırma & & $2.87 \pm 2.80$ & & & \pm 1.64 & 4406.6 & -9.92 & 0.000 \\
\hline Aşırı aktif mesane & & $4.77 \pm 5.08$ & & 11. & \pm 3.97 & 4011 & -10.36 & 0.000 \\
\hline $\begin{array}{l}\text { İdrar akış hızında } \\
\text { yavaşlama }\end{array}$ & & $0.55 \pm 1.22$ & & & \pm 1.99 & 5716.5 & -8.89 & 0.000 \\
\hline Toplam Puan & & $8.19 \pm 8.55$ & & 19.8 & \pm 6.57 & 3780 & -10.64 & 0.000 \\
\hline & & & Medeni Dur & nu & & & & \\
\hline & & Evli (n=247 & & Bekar/ & ul $(n=73)$ & & & \\
\hline & & $\mathrm{X} \pm \mathrm{SD}$ & & & $\mathrm{SD}$ & $\mathrm{U}$ & $\mathrm{z}$ & $\mathrm{p}$ \\
\hline Stres tipi idrar kaçırma & & $5.19 \pm 2.25$ & & 0.8 & \pm 2.20 & 2172 & -10.00 & 0.000 \\
\hline Aşırı aktif mesane & & $9.36 \pm 4.92$ & & 1.3 & \pm 3.63 & 1935.5 & -10.29 & 0.000 \\
\hline $\begin{array}{l}\text { İdrar akış hızında } \\
\text { yavaşlama }\end{array}$ & & $1.51 \pm 1.86$ & & & \pm 0.45 & 3991.5 & -7.88 & 0.000 \\
\hline Toplam Puan & & $16.05 \pm 8.21$ & & & \pm 6.05 & 1872 & -10.38 & 0.000 \\
\hline
\end{tabular}

\footnotetext{
* Kruskal-Wallis Analizi SD=3 ** Mann-Whitney U SD=2
} 
Tablo 6. Kadınların Obstetrik Özelliklerine Göre ÜSP Toplam ve Alt Boyut Puan Ortalamalarının Karşılaştırılması

\begin{tabular}{|c|c|c|c|c|c|}
\hline \multirow{4}{*}{ ÜSP } & \multicolumn{3}{|c|}{ Obstetrik Özellikler } & & \\
\hline & \multicolumn{3}{|c|}{ Gebelik Sayısı } & & \\
\hline & Hiç gebe kalmamış $(n=73)$ & 1-2 gebelik $(n=110)$ & 3 gebelik ve $\uparrow(n=137)$ & & \\
\hline & $\mathrm{X} \pm \mathrm{SD}$ & $\mathrm{X} \pm \mathrm{SD}$ & $\mathrm{X} \pm \mathrm{SD}$ & $\mathrm{X}_{\mathrm{KW} *}^{2}$ & $\mathrm{p}$ \\
\hline \multirow[t]{4}{*}{$\begin{array}{l}\text { Stres tipi idrar kaçırma } \\
\text { Aşırı aktif mesane } \\
\text { İdrar akış hızında } \\
\text { yavaşlama } \\
\text { Toplam Puan }\end{array}$} & $\begin{array}{c}0.36 \pm 1.53 \\
0.51 \pm 2.24 \\
0.01 \pm 0.12 \\
88 \pm 3.83\end{array}$ & $\begin{array}{c}4.52 \pm 2.20 \\
7.77 \pm 4.74 \\
0.82 \pm 1.28 \\
13.12 \pm 7.50\end{array}$ & $\begin{array}{c}6.43 \pm 1.32 \\
12.11 \pm 3.23 \\
2.49 \pm 2.08 \\
21.03 \pm 5.68\end{array}$ & $\begin{array}{l}168.05 \\
172.92 \\
126.04 \\
181.18\end{array}$ & $\begin{array}{l}0.000 \\
0.000 \\
0.000 \\
0.000\end{array}$ \\
\hline & \multicolumn{3}{|c|}{ Doğum Sayısı } & & \\
\hline & Hiç doğum yapmamış $(n=73)$ & 1-2 doğum $(n=142)$ & 3 doğum ve $\uparrow(n=105)$ & & \\
\hline & $\mathrm{X} \pm \mathrm{SD}$ & $\mathrm{X} \pm \mathrm{SD}$ & $\mathrm{X} \pm \mathrm{SD}$ & $\mathrm{X}_{\mathrm{KW}^{*}}$ & $\mathrm{p}$ \\
\hline $\begin{array}{l}\text { Stres tipi idrar kaçırma } \\
\text { Aşırı aktif mesane } \\
\text { İdrar akış hızında } \\
\text { yavaşlama } \\
\text { Toplam Puan }\end{array}$ & $\begin{array}{l}0.36 \pm 1.53 \\
0.51 \pm 2.24 \\
0.01 \pm 0.12 \\
0.88 \pm 3.83\end{array}$ & $\begin{array}{c}4.19 \pm 2.21 \\
7.17 \pm 4.71 \\
0.64 \pm 1.15 \\
12.00 \pm 7.36\end{array}$ & $\begin{array}{c}6.25 \pm 1.46 \\
11.58 \pm 3.69 \\
2.25 \pm 1.99 \\
20.08 \pm 6.17\end{array}$ & $\begin{array}{l}172.32 \\
174.12 \\
130.42 \\
183.06\end{array}$ & $\begin{array}{l}0.000 \\
0.000 \\
0.000 \\
0.000\end{array}$ \\
\hline
\end{tabular}

*Kruskal-Wallis Analizi SD=2

anlamlıdır. Standardize edilmiş regresyon katsayısına göre $($ Beta $=\beta)$ yordayıc1/ etkileyen değişkenlerin önem sırası; diyabet, doğum sayısı, BKİ ve yaş şeklindedir (Tablo 8).

Tablo 7. Kadınların Obstetrik Özelliklerine Göre ÜSP Toplam ve Alt Boyut Puanlarının İlişkisi

\begin{tabular}{|l|c|c|c|}
\hline \multicolumn{4}{|c|}{ Pearson's r } \\
\hline \multicolumn{1}{|c|}{ ÜSP } & $\begin{array}{c}\text { Gebelik } \\
\text { Sayısı }\end{array}$ & $\begin{array}{c}\text { Doğum } \\
\text { Sayısı }\end{array}$ & p \\
\hline Stres üriner inkontinans & 0.76 & 0.77 & 0.000 \\
\hline Aşırı aktif mesane & 0.74 & 0.75 & 0.000 \\
\hline Idrar akış hızı & 0.58 & 0.59 & 0.000 \\
\hline Toplam puan & 0.77 & 0.78 & 0.000 \\
\hline
\end{tabular}

*Pearson momentler çarpımı korelasyon analizi

\section{TARTIŞMA}

Sunulan çalışma, kadınlarda BKİ'ni belirlemek ve BKI'nin üriner şikayetler ile ilişkisini araştırmak amac1 ile yapılmıştır. Çin'deki kadınlarda, potansiyel üriner inkontinans risk faktörlerini incelemek amaciyla Zhu, Lang, Wang, Han ve Huang (2008)'ın çalışması, Nisan-Haziran 2005 tarihinde, toplam 5300 kadında yapılmıştır. Yapılan çalışmada, obezitenin stres üriner inkontinansı için bir risk faktörü oluşturduğu belirlenmiştir. Üriner inkontinansın kadınların yaşamını etkileyen büyük bir sorun olduğu gözlemlenmiştir. Yaptığımız çalışma sonucuna göre de obezitenin stres üriner inkontinans için risk faktörü olduğu belirlenmiştir.

Tablo 8. Linear Regresyon Analizine Göre Kadınlarda ÜSP Puanını Etkileyen Risk Faktörleri

\begin{tabular}{|l|c|c|c|c|c|c|c|}
\hline \multirow{2}{*}{ Değişkenler } & & & & & \multicolumn{2}{|c|}{$\% 95$ CI } \\
\cline { 5 - 8 } & B & Std. Hata & Beta & $\mathbf{t}$ & $\mathbf{p}$ & Alt değer & Üst değer \\
\hline Yaş & -20.318 & 1.343 & & -15.134 & 0.000 & -22.960 & -17.677 \\
\hline BKİ & 0.132 & 0.028 & 0.196 & 4.794 & 0.000 & 0.078 & 0.186 \\
\hline Diyabet & 0.859 & 0.053 & 0.487 & 16.158 & 0.000 & 0.755 & 0.964 \\
\hline Doğum sayıs1 & 2.963 & 0.597 & 0.145 & 4.965 & 0.000 & 1.789 & 4.137 \\
\hline
\end{tabular}


Obezite ile üriner inkontinans arasında, birçok çalışmada, anlamlı bir ilişki bulunmuştur (Altunkaynak ve Özbek 2007). Bart ve ark. (2008)'nın Fransa'da yapmış olduğu çalışmada, üriner inkontinans prevalansı \%44 olarak saptanmıştır. Ayrıca, inkontinansı olan morbid obez kadınlarda ciddi kilo kaybının intravezikal basıncı önemli ölçüde azalttı̆̆ı gözlemlenmiştir. $\mathrm{Bu}$ da obeziteye bağlı karın içi basıncın stres üriner inkontinansta önemli olduğunu vurgulayan bir basamaktır (Yalçın 2009).

Üriner inkontinans semptomlarını gösteren kadınları değerlendirmek amaciyla Mishra, Hardy, Cardozo ve Kuh (2008)'un yapmış olduğu çalışma sonucuna göre kadın hem genç hem de obez ise bu risk iki kat arttığı, çalışmanın sonunda, bulunmuştur.

Gebelik, çoğunlukla ilk gebelik, kadına yaptığı hormonal ve fiziksel değişimlerden dolayı, stres üriner inkontinansın oluşmasında etkilidir. Bir çalışmada, gebelik ilerledikçe üriner inkontinans semptomlarının arttığ 1 ve buna bağlı olarak da pelvik destek dokularında değişikliğe neden olabileceği söylenmiştir (Yalçın 2009). Yaptığımız çalışmada da gebelik sayısı ile üriner inkontinans arasında anlamlı bir artış gözlemlenmiştir.

2005 yılında, yapılan bir çalışmada 20 yaşın üstündeki kadınların \%8.8'inin diyabet olduğu saptanmıştır. Bu kadınların \%50'sinde üriner inkontinans semptomları mevcuttur. Bu çalışmada da obezite ile üriner inkontinans ilişkisi anlamlı bulunmuştur (Lawrence, Lukacz, Liu, Nager ve Luber 2007).

Değişik ülkelerde yapılan bu çalışmalar sonucunda aşırı aktif mesanenin yaş ile doğru orantılı olarak arttığ gözlemlenmiştir (Coyne, Sexton ve Thompson 2009; Irwin ve ark. 2006; Lugo ve ark. 2013; Wang ve ark. 2011). Yapılan çalışmamızda da aşırı aktif mesane bulgusu yaş ile anlamlı olarak artmaktadır.

\section{SONUÇ VE ÖNERILLER}

Sonuç olarak, çalışmamızda literatür ile benzer şekilde diyabet, doğum sayısı, BKİ ve yaş üriner şikayetleri etkileyen faktörler olarak belirlenmiştir.
Bu sonuçlar doğrultusunda;

- Tüm kadınlar inkontinansa neden olabilecek risk faktörleri (doğum öyküsü, beslenme, ailesel öykü v.b.) açısından değerlendirilmeli, ayrıca üriner inkontinans bulguları ve risk faktörleri, üriner inkontinansdan korunmaya ilişkin eğitilmeli ve kadınlar bilinçlendirilmeli,

- Kadın yaşamında önemli bir yer tutan gebelik, doğum, lohusalık ve menopoz dönemlerinde inkontinans ve obesiteyi önleme ve korunma eğitimleri kadınlara verilmeli,

- Hastaların diyet alışkanlıkları düzenlenmesi önerilebilir.

\section{KAYNAKLAR}

Afşin, Y. (2008). Üriner inkontinanslı kadınların tedavisinde tolterodin ve trospium chloride tedavilerinin karşılaştırılması. Yayınlanmamış Uzmanlık Tezi, Dr. Lütfi Kırdar Kartal Eğitim ve Araştırma Hastanesi, İstanbul.

Altunkaynak, B. Z., Özbek, E. (2007). Obezite: Nedenleri ve tedavi seçenekleri. Dicle Tip Dergisi, 34(2): 144-149.

Uslu-Atlaş, Z. G. (2008). Stres üriner inkontinas hastalarında midüretral transobturatur bant (TOT) cerrahisi klinik gözlem ve erken dönem sonuçları. Yayınlanmamış Uzmanlık Tezi, İstanbul Göztepe Eğitim ve Araştırma Hastanesi, İstanbul.

Bart, S. ve ark. (2008). Stress urinary incontinence and obesity. Progres En Urologie, 18(8): 493-498.

Coyne, K. S. ve ark. (2009). The prevalence of lower urinary tract symptoms (LUTS) in The USA, The UK and Sweden: Results from the epidemiology of LUTS study. BJU International, 104(3): 352360 .

Coyne, K. S. ve ark. (2011). National community prevalence of overactive bladder in the United States stratified by sex and age. Urology, 77(5): 1081-1087.

Çankaya, A., Oskay, Ü. (2014). Aşırı aktif mesane tanısı almış kadınlarda mesane günlüklerinin incelenmesi. Gülhane Tip Dergisi, 56(3): 169-173.

Haylen, B. T. ve ark. (2010). An International Urogynecological Association (IUGA)/ International Continence Society (ICS) joint report on the terminology for female pelvic floor dysfunction. International Urogynecology Journal, 21(1): 5-26.

Irwin, D. E. ve ark. (2006). Population-based survey of urinary incontinence, overactive bladder, and other lower urinary tract symptoms in five countries: Results of the EPIC study. European Urology, 50(6): 1306-1314. 
Lawrence, J. M., Lukacz, E. S., Liu, I. L. A., Nager, C. W., Luber, K. M. (2007). Pelvic floor disorders, diabetes, and obesity in women findings from the Kaiser permanente continence associated risk epidemiology study. Diabetes Care, 30(10): 2536-3541.

Lugo-Salcedo, F. ve ark. (2013). Assessment of female prevalence of overactive bladder $(\mathrm{OAB})$ in Barcelona using a self-administered screening questionnaire: The Cuestionario de autoevaluación del control de la Vejiga (CACV). International Urogynecology Journal, 24(9): 1559-1566.

Mishra, G. D., Hardy, R., Cardozo, L., Kuh, D. (2008). Body weight through adult life and risk of urinary incontinence in middleaged women: Results from a British prospective cohort. International Journal of Obesity, 32(9): 1415-1422.

Öztürk, G. Z., Toprak, D., Basa, E. (2012). 35 yaş üzeri kadınlarda üriner inkontinans sıklığı ve etkileyen faktörlerin değerlendirilmesi. Şişli Etfal Hastanesi Tıp Bülteni, 46(4): 170-176.

T. C. Sağlık Bakanlığı Türkiye Halk Sağlığı Kurumu (2013). Türkiye sağlıklı beslenme ve hareketli hayat programı, http://beslenme. gov.tr/content/files/home/turkiye_saglikli_beslenme_ve_hareketli_hayat_programi.pdf. (22.08.2015).
Wang, Y. ve ark. (2011). Prevalence, risk factors, and impact on health related quality of life of overactive bladder in China. Neurourology and Urodynamics, 30(8): 1448-1455.

Yalçın, Ö. (2009). Temel Ürojinekoloji. 1. basım, Nobel Tıp Kitabevi, İstanbul.

Yüksel, A. (2016). Bariatrik cerrahi operasyonu geçiren morbid obez bir hastanın 3 y1l sonraki beslenme durumu: Olgu sunumu. İmir Kâtip Çelebi Üniversitesi Sağllk Bilimleri Fakültesi Dergisi, 1(1): 39-45.

Zhang, W. ve ark. (2006). Prevalence and risk factors of overactive bladder syndrome in Fuzhou Chinese women. Neurourology and Urodynamics, 25(7): 717-721.

Zhu, L., Lang, J., Wang, H., Han, S., Huang, J. (2008). The prevalance of and potential risk factors for female urinary incontinence in Beijing, China. The Journal of The North American Menopause Society, 15(3): 566-569. 